\title{
Patellofemoral kinetics during running in Heelless and conventional running shoes.
}

Conference Paper · January 2015

CITATIONS

0

4 authors:

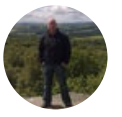

Andrew Greenhalgh

University of Hertfordshire

63 PUBLICATIONS 333 CITATIONS

SEE PROFILE

Roozbeh Naemi

Staffordshire University

105 PUBLICATIONS 268 CITATIONS

SEE PROFILE
READS

62

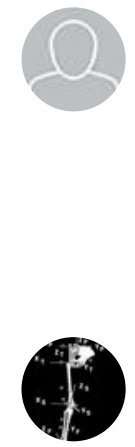

Nachiappan Chockalingam

Staffordshire University

447 PUBLICATIONS 1,384 CITATIONS

SEE PROFILE

Jonathan Sinclair

University of Central Lancashire

274 PUBLICATIONS 918 CITATIONS

SEE PROFILE

Some of the authors of this publication are also working on these related projects:

Project

Project
03/01/2018 View project

Manufacturing and finite element assessment of a novel pressure reducing insole for Diabetic Neuropathic patients View project 
Patellofemoral kinetics during running in Heelless and conventional running shoes. Andrew Greenhalgh ${ }^{\mathrm{a}}$, Nachiappan Chockalingam ${ }^{\mathrm{b}}$, Roozbeh Naemi ${ }^{\mathrm{b}}$ and Jonathan Sinclair ${ }^{\mathrm{c}}$

${ }^{a}$ London Sport Institute, Middlesex University, London, UK

${ }^{\mathrm{b}}$ Centre for Sport Health and Exercise Research, Faculty of Health Sciences, Staffordshire

University, Stoke on Trent, UK

${ }^{c}$ Division of Sport Exercise and Nutritional Sciences, University of Central Lancashire, UK

\section{Introduction}

Recreational running is a popular recreational activity often used to improve health and wellbeing of the participants. Sustaining injuries that stop people from running can therefore be detrimental. One of the most prevalent overuse injuries in recreational running populations (Chang et al., 2012; Ellapen et al., 2013) has been reported as patellofemoral pain which is a result of the pressure experienced between the posterior surface of the patella and the anterior distal aspect of the femur.

Footwear designers have attempted to develop shoes to reduce rate of injuries in populations. One such design is a heelless shoe that appears to adjust the footstrike pattern of the participant during running (Sinclair et al., 2014). Such adaptation to movement may influence knee joint kinetics and kinematics altering the pressure between the patella and the femur.

\section{Purpose of the study}

The purpose of this study was to test if running in heelless shoes compared to conventional running shoes will significantly affect the patella contact loading.

\section{Methods}

Participants

Twelve male runners (age 27.22 \pm 4.76 years, height $1.79 \pm 0.09 \mathrm{~m}$ and body mass $78.65 \pm$
$8.26 \mathrm{~kg}$, shoe size 8-10 UK) consented to take part in this study.

Participants ran at $4.0 \mathrm{~m} . \mathrm{s}^{-1} \pm 5 \%$ over an embedded force platform (Kistler National Instruments, Model 9281CA) sampling at $1000 \mathrm{~Hz}$ with their right foot (Sinclair et al., 2014). Running velocity was quantified using timing gates. Runners completed five successful trials in each footwear condition (Saucony pro grid guide II and heelless $\left(\right.$ Healus $\left.^{\mathrm{TM}}\right)$ ).

Kinematic data was captured at $250 \mathrm{~Hz}$ via an eight camera motion analysis system (Qualisys). To model the body extremity segments in six degrees of freedom the calibrated anatomical systems technique was used (Cappozzo et al., 1995).

Ground reaction force and marker trajectories were filtered at 50 and $12 \mathrm{~Hz}$ respectively using a low pass Butterworth 4th order zerolag filter and analysed using Visual 3D software (C-Motion) .

Patellofemoral contact force (PCF) (B.W) was estimated through the biomechanical model of Ho et al., (2012) using knee flexion angle (KFA) and knee extensor moment (KXT). The moment arm of the quadriceps was calculated using a non-linear equation, based on cadaveric information presented by van Eijden et al., (1986). PCF was estimated using 
the Quadriceps force and a constant which was described in relation to KFA using a curve fitting technique based on the nonlinear equation described by Eijden et al., (1986). Patellofemoral pressure (PP) (MPa) was calculated using the PCF divided by the patellofemoral contact area (Ho et al., 2012),

Differences in knee loading parameters between the two footwear conditions were examined using repeated measures ANOVA $($ alpha $=0.05)$.

\section{Results}

Table 1 presents the knee kinetic variables obtained as a function of footwear. The results indicate that when compared to a conventional footwear (control shoe), running in the heelless footwear significantly reduces the knee loading parameters.

Table 1: Knee joint kinetics (Means \pm standard deviations) as a function of footwear.

\begin{tabular}{|c|c|c|c|c|c|}
\hline & \multicolumn{2}{|c|}{ Conventional } & \multicolumn{2}{c|}{ Heelless } & \\
\hline & Mean & SD & Mean & SD & \\
\hline $\begin{array}{c}\text { Peak KXT } \\
\text { (Nm.kg) }\end{array}$ & 3.15 & 0.64 & 2.98 & 0.59 & $*$ \\
\hline $\begin{array}{c}\text { Peak PCF } \\
\text { (B.W) }\end{array}$ & 4.25 & 0.99 & 4.04 & 0.87 & $*$ \\
\hline $\begin{array}{c}\text { Peak PP } \\
\text { (MPa) }\end{array}$ & 13.41 & 2.66 & 12.85 & 2.51 & $*$ \\
\hline
\end{tabular}

Notes: ${ }^{*}=$ Significant difference

The results show that peak KXT was significantly higher $(\mathrm{p} \leq 0.05, \eta 2=0.52)$ in the conventional footwear compared to Heelless. Similarly, peak PCF $(\mathrm{p} \leq 0.05, \eta 2=0.40)$ and PP $(p \leq 0.05, \eta 2=0.39)$ were also shown to be significantly greater in the conventional footwear.

\section{Discussion and conclusion}

The results of this study suggest that the heelless running shoes may reduce the likelihood of athletes sustaining discomfort and overuse injuries at the patellofemoral joint. It should be noted that whilst a reduction in susceptibility to injury appears to be prevalent in the results of this research, longitudinal studies on the effects of such footwear use are warranted. Alteration of knee joint kinetics may influence the kinetic chain and loading of the musculoskeletal system in other areas thus a holistic approach to footwear choice is warranted. However for athletes with a history of knee pain the heelless footwear may warrant selection over conventional footwear.

\section{References}

Cappozzo, A. et al. (1995). Clin Biomech, 10 (4), 171-178

Chang, W.-L. et al. (2012). Phys Ther Sport, 13 (3), 170-174 Orthop Sport Phys Ther, 41 (12), 914-919. Van Eijden, et al. (1986). J biomech, 19(3), 219-229

Ellapen, T. J. et al, (2013). South African J of Sport Med, 25 (2), 39-43

Ho, K. Y. et al, (2012). Gait and Posture, 36, 271-275

Sinclair, J. et al, (2013). Footwear Sci, 5, 4553

Sinclair, J. et al. (2014). Footwear Sci, 1-7 